\title{
THE FORMATION OF BRINE DRAINAGE FEATURES IN YOUNG SEA ICE*
}

\author{
By Lars Ingolf Eide $\dagger$ and Seelye Martin \\ (Department of Oceanography WB-ro, University of Washington, Seattle, Washington 98 195, \\ U.S.A.)
}

\begin{abstract}
Laboratory experiments on the growth of sea ice in a very thin plastic tank filled with salt water, cooled from above and insulated with thermopane, clearly show the formation and development of brine drainage channels. The sea-water freezing cell is $0.3 \mathrm{~cm}$ thick by $35 \mathrm{~cm}$ wide by $50 \mathrm{~cm}$ deep; the thermopane insulation permits the ice interior to be photographed. Expcrimentally, we observe that vertical channels with diameters of $\mathrm{I}$ to $3 \mathrm{~mm}$ and associated smaller feeder channels extend throughout the ice sheet. Close examination of the brine channels show that their diameter at the ice-water interface is much narrower than higher up in the ice, so that the channel has a "neck" at the interface. Further, oscillations occur in the brine channels, in that brine flows out of the channel followed by a flow of sea-water up into the channel. Theoretically, a qualitative theory based on the difference in pressure head between the brine inside the ice and the sea-water provides a consistent explanation for the formation of the channels, and the onset of a convective instability explains the existence of the neck. Finally, an analysis based on the presence of the brine-channel neck provides an explanation for the observed oscillations.
\end{abstract}

RÉsumé. La formation des réseaux de drainage, de la saumure dans la jeune glace de mer. Des expériences de laboratoires ont été conduites sur la croissance de la glace de mer dans un réservoir de plastique très fin, rempli d'eau salée, refroidi par au-dessus et isolé avec un panneau thermique. Elles ont clairement montré la formation et le développement de canaux de drainage de la saumure. La cellule de congélation de l'eau a $0,3 \mathrm{~cm}$ d'épaisseur, $35 \mathrm{~cm}$ de large et $50 \mathrm{~cm}$ de profondeur; le panneau isolant permet de photographier la glace à l'intérieur. Expérimentalement, nous observone des canaux verticaux avec des diamètres de 1 à 3 $\mathrm{mm}$ associés à des canaux d'alimentation plus petits étendus à travers la feuille de glace. Un examen attentif des canaux de saumure montre que leur diamètre à l'interface eau-glace est beaucoup plus faible que plus haut dans la glace, de sorte que le canal présente un étranglement à l'interface. Plus tard, il se produit des oscillations dans les canaux de saumure par lesquels, à l'écoulement de la saumure par le canal, succède un flot d'eau de mer montant dans le canal. Sur le plan théorique, une hypothèse qualitative basée sur la différence de pression entre la saumure à l'intérieur de la glace et l'eau de mer, donne une explication satisfaisante pour la formation de canaux, et l'apparition d'une instabilité de convection explique l'existence de l'étranglement. Finalement, une analyse basée sur la présence de l'étranglement des canaux de saumure procure une explication des oscillations observées.

Zusammenfassung. Die Bildung von Systemen zur Salzsole-Drainage in frischem Meereis. Laboruntersuchungen über das Wachstum von Meereis in einem sehr dünnen, mit Salzwasser gefüllten Plastikbehülter, der von oben gekühlt und mit Thermopane isoliert war, zeigen deutlich die Bildung und Ausbreitung von DrainageKanälen für die Salzsole. Die Gefrierzelle für das Meerwasser ist $0,3 \mathrm{~cm}$ breit, $35 \mathrm{~cm}$ lang und $50 \mathrm{~cm}$ tief; das Eis im Inneren kann durch die Thermopane-Isolierung hindurch photographiert werden. Im Experiment lässt sich beobachten, dass vertikale Kanäle mit Durchmessern von $\mathrm{I}-3 \mathrm{~mm}$ und dazugehörige kleinere Seitenkanäle sich durch die gesamte Eisschicht erstrecken. Bei näherer Betrachtung der Solekanäle ist zu erkennen, dass deren Durchmesser an der Grenzfläche zwischen Eis und Wasser viel kleiner ist als weiter oben im Eis, dass also der Kanal an der Grenzfläche einen "Flaschenhals" besitzt. Es zeigt sich weiterhin, dass in den Solekanälen Schwingungen stattfinden derart, dass einem Ausfluss von Sole aus dem Kanal ein Eindringen von Meerwasser nach oben in den Kanal folgt. Eine qualitative Theorie, die auf der Druckdifferenz zwischen der Salzsole im Eis und dem Meerwasser beruht, liefert eine folgerichtige Erklärung für die Kanalbildung; die Annahme einer konvektiven Instabilität erklärt das Vorhandensein der Verengung. Schliesslich liefert eine Analyse, die von dem Vorhandensein der Kanalverengung ausgeht, eine Erklärung für die beobachteten Schwingungen.

\section{INTRODUCTION}

Beginning with the great polar expeditions of the last century, observers have noted that sea ice is much fresher than sea-water. For example, both the field observations of Malmgren (1927) and Weeks and Lee (1962), and the unpublished laboratory investigations of G. F. N. Cox (private communication in 1973), show that the salinity of young sea ice decreases from roughly $20 \%$ immediately after its formation to $5 \%$ after a period of 2 to 4 weeks.

* Department of Oceanography, University of Washington, Contribution No. 31 I ; Department of Atmospheric Sciences, University of Washington, Contribution No. 768 .

† Now at Vassdrags- og Havnelaboratoriet, Klæbuveien 153, 7000 Trondheim, Norway. 
Because much of the brine inside of sea ice is contained in small brine pockets, Whitman's (1926) theory of brine pocket migration was long thought to explain how sea ice lost its salt. Untersteiner ( 1967$)$, however, pointed out that the pocket migration is far too slow to account for the observed changes in salinity, and suggested that "brine expulsion" and "gravity drainage", both of which we define below, account for the rapid decrease in salt content.

"Brine expulsion" occurs when the temperature of the brine pockets decreases, which causes some of the brine to freeze. Because the specific volume of ice is approximately $10 \%$ greater than that of water, freezing increases the pressure inside the pocket, thus presumably forcing some of the brine from the pocket. In "gravity drainage", the greater weight of the brine relative to that of the sea-water tends to drive the brine out of the ice, thus causing the generally observed absence of salt above the water-line (see Untersteiner ( 1967 ) and Cox and Weeks (1974) for examples). Both expulsion and gravity drainage require interconnected tubes or channels through which the brine can drain. Bennington (1963, 1967) and Lake and Lewis (1970, hereafter abbreviated LL) observed such brine channels in field investigations, but at the present time, there has been neither a detailed laboratory nor theoretical study of how these channels form.

In the present paper, we describe a laboratory study of the drainage of young sea ice which yields a qualitative theoretical model of the formation and evolution of brine drainage channels. Because of brine pockets, sections of sea ice with a thickness greater than about I $\mathrm{cm}$ are translucent. Therefore, to study the formation of drainage channels, using the apparatus described in the next section, we grew an ice sheet with a width of $35 \mathrm{~cm}$, a depth of up to $50 \mathrm{~cm}$, but a thickness of only $0.3 \mathrm{~cm}$, so that we were able to see through the ice and to photograph the development of the brine drainage channels. Our observations yielded the unexpected result that once the channels form, the flow in them is oscillatory in that first brine pours out of the channel, then sea-water flows up into the ice, and so forth.

Following the discussion of our observations, we present a qualitative model for the formation of the observed brine channels based on gravity drainage; a model suggested by Röthlisberger's (1972) and Shreve's (1972) (hereafter abbreviated as R and S) models for the drainage of temperate glaciers. We finally show that the geometry of the brine drainage channels is such that the channels are unstable to oscillations similar to those observed.

\section{The EXPERIMENT}

Figure $\mathrm{I}$ is a schematic diagram of our apparatus. The inner freezing cell, which was built from $1.3 \mathrm{~cm}$ thick sheets of clear acrylic plastic ("Plexiglas"), has a width of $35 \mathrm{~cm}$, a depth of $50 \mathrm{~cm}$, and a thickness of only $0.3 \mathrm{~cm}$. Besides making the ice transparent, this particular choice of cell thickness meant that the ice sheet was several dendrite diameters thick, so that triple grain boundaries occurred inside the ice. We insulated this cell with $3.75 \mathrm{~cm}$ of dry air divided into six vertical concentric layers on the thermopane principle described in Grober and others (I96I).

At the top of the cell, cold alcohol circulated through a square copper tube insulated with polyurethane. As we show below, the growing ice sheet and the "Plexiglas" have similar transient thermal properties. For this reason, the copper tube extended over both the water and the plastic of the box. To smooth out thermal irregularities in the tube, a $0.3 \mathrm{~cm}$ thick copper plate extended $4 \mathrm{~cm}$ from the bottom of the tube into the cell. The sea ice grew from the bottom of this plate. At the bottom of the cell, drainage holes provided for an overflow tube, the introduction of dye into the cell, and the replacement of the dense brine generated by the ice growth with sea-water. During an experiment, to minimize both conductive and convective heat transfer from the ice, we placed the entire apparatus in a cold dark room at a temperature of $-1.5^{\circ} \mathrm{C}$. We filled the cell with a $32 \% \mathrm{NaCl}$ solution, hereafter called seawater, which has a freezing temperature of $-\mathrm{r} .8^{\circ} \mathrm{C}$. When the sea-water had cooled to 


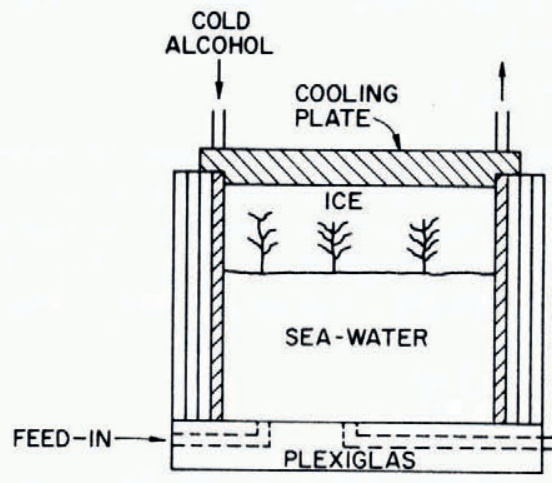

(a)

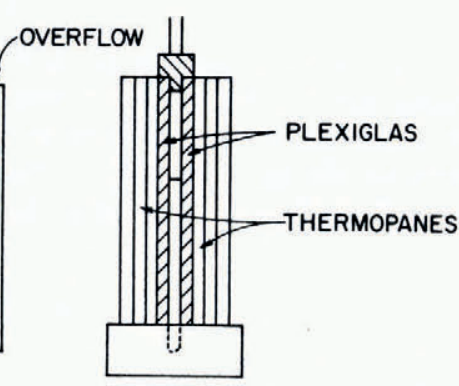

(b)

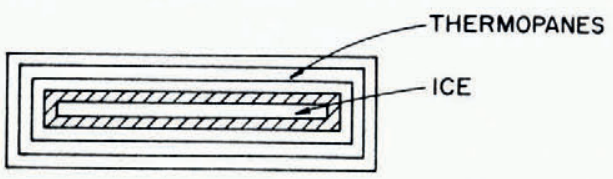

(c)

Fig. 1. A schematic diagram of the apparatus. For simplicity, we have not shown all of the thermopanes.

room temperature, we circulated alcohol at a temperature of $-17^{\circ} \mathrm{C}$ through the copper tube and thereby initiated ice growth.

We designed the tank so that the ice grown in it resembled natural sea ice. Because the ice growth depends on the thermal properties of the dry air, "Plexiglas", and the ice-water mixture, we next discuss how these properties influenced the tank design.

Table I lists both the thermal conductivities $(k)$ and diffusivities $(\kappa)$ for these four materials. The $k$ s govern the magnitude of the steady heat fluxes; the $\kappa \mathrm{s}$, the propagation speed of a transient temperature disturbance. Since our experiment is a transient one, in that beginning at some time $t=0$ we cool the freezing cell from above, the magnitude of both the $k \mathrm{~s}$ and $\kappa \mathrm{s}$ are important. To estimate the effects of the different materials on the ice growth, we assume that the transient heat-flows in each material are one-dimensional in the vertical. For onedimensional heat flow in the $z$-direction, Carslaw and Jaeger (1959, chapter 2) show that

TABle I. Thermal. PRoperties of the Materials USEd in the construction OF OUR EXPERIMENTAL CELL

\begin{tabular}{|c|c|c|}
\hline Material & $\begin{array}{c}\text { Thermal conductivity } \\
\qquad k \\
\qquad \mathrm{~W} \mathrm{~m}^{-1} \mathrm{deg}^{-1}\end{array}$ & $\begin{array}{c}\text { Thermal diffusivity } \\
\mathrm{m}^{2} \mathrm{~s}^{-1}\end{array}$ \\
\hline $\operatorname{air}^{1}$ & $2.3 \times 10^{-2}$ & $1.6 \times 10^{-5}$ \\
\hline water $^{2}$ & $5.9 \times 10^{-1}$ & $1.4 \times 10^{-7}$ \\
\hline ice $^{2}$ & 2.2 & $1.1 \times 10^{-6}$ \\
\hline $\begin{array}{l}\text { "Plexiglas"'3 } \\
\quad \text { (polymethylmethacrylate) }\end{array}$ & $1.7 \times 10^{-1}$ & $1.0 \times 10^{-7}$ \\
\hline
\end{tabular}


the temperature disturbance generated by a temperature change at $z=0$ at time $t=0$ propagates a distance $z$ in a time $t$ according to

$$
z \approx(\kappa t)^{\frac{1}{2}} \text {. }
$$

Equation ( 1 ) holds for the dry air and the "Plexiglas"; but because the sea-water is very near its freezing point, an initial cooling causes ice growth so that Equation (I) does not apply. From a calculation of the growth rate of the ice front, however, we can also estimate an equivalent $\kappa$ for the growing ice. If the temperature profile in the ice sheet is linear, then Carslaw and Jaeger (1959, § I 1.2) show that the thickness $h$ of the ice sheet increases according to

$$
h=\left(\frac{2 k_{\mathrm{i}} \Delta T t}{L \rho_{1}}\right)^{\frac{1}{2}},
$$

where $\Delta T$ is the temperature difference between the cold plate and the sea-water, $L$ is the latent heat, and $\rho_{i}$ is the ice density.

For the experimental value of $\Delta T \approx{ }_{1} 5^{\circ} \mathrm{C}$, and using $L=335 \mathrm{~kJ} \mathrm{~kg}^{-1}$ and $\rho_{\mathrm{i}} \approx 0.9^{2}$ $\mathrm{Mg} \mathrm{m}^{-3}$, we find that $h$ measured in meters is given by

$$
h \approx\left(2.2 \times 10^{-7} t\right)^{\frac{1}{2}} .
$$

Comparison of Equations ( $\mathrm{r}$ ) and (3) shows that the equivalent $\kappa$ of the growing sea ice is $2.2 \times 10^{-7} \mathrm{~m}^{2} \mathrm{~s}^{-1}$. Therefore the ice front grows at approximately the same rate as the speed at which the temperature disturbance propagates in the "Plexiglas". Because of the similar properties of the "Plexiglas" and the growing ice sheet, the temperature field should be nearly horizontally uniform across the $0.3 \mathrm{~cm}$ thickness of the sheet.

The use of dry air (or any common gas) in the thermopane complicates the ice growth and is the reason for the use of $1.3 \mathrm{~cm}$ thick Plexiglas for the cell walls. Table I shows that air has both the smallest $k$ and largest $\kappa$ of the four materials. The small $k$ of dry air means that the heat flow from the room to the ice is very small compared to almost any other transparent material. The large $\kappa$ of dry air, which is two orders of magnitude greater than that of "Plexiglas", means that the cold disturbance propagates much faster in air than in "Plexiglas". In trial experiments, we found if the thickness of the "Plexiglas" wall between the air and water was only of order I $\mathrm{mm}$, then the rapid propagation of the cold wave in the air relative to the ice and water caused loose crystals to freeze in the water ahead of the ice front. The insulating effect of the $1.3 \mathrm{~cm}$ "Plexiglas" cell walls, however, prevented this heat transfer from the air to the sea-water so that the ice grew as an advancing planar front.

The heat flow from the room to the water through the dry air limited the ice growth. When the ice reached a thickness of about $20 \mathrm{~cm}$, the heat removed by the cold plate at the top of the cell was of the same order as the heat flow in through the sides over the broad area of the thermopane. Therefore, ice of this thickness ceased to grow, and we observed both internal melting inside the ice and some distortion of the interface.

To record the growth of the ice sheet, we used both a time-lapse movie camera and a $35 \mathrm{~mm}$ still camera. The photographic lighting consisted of two flood lights placed behind a diffusing screen on one side of the tank, with the cameras on the opposite side. We only turned the lights on while we took a photograph; otherwise the tank was left in the dark. For the time-lapse films, the camera turned the lights on and off automatically. Using these techniques, we initially took crossed-polaroid photographs. Figure 2 shows such a photograph for a typical ice sheet in our test cell. The ice resembles natural sea ice in several ways. First, the ice sheet is made up of the columnar wedge-shaped crystals described by Bennington ( 1963 , see especially his figure 14) as typical of sea ice with a horizontal $c$-axis. Second, from micro-photographs, we found that the individual dendrites which make up the crystals have a diameter of the order of $1-5 \times 10^{-1} \mathrm{~mm}$, which is in the range reported by Lofgren and 
Weeks (1969). Third, the photograph shows the small, black brine pockets and the white randomly-oriented crystals described by LL. The evidence from this and other similar crossedpolaroid photographs is that the ice grown in our cell exhibits many of the features of natural sea ice.

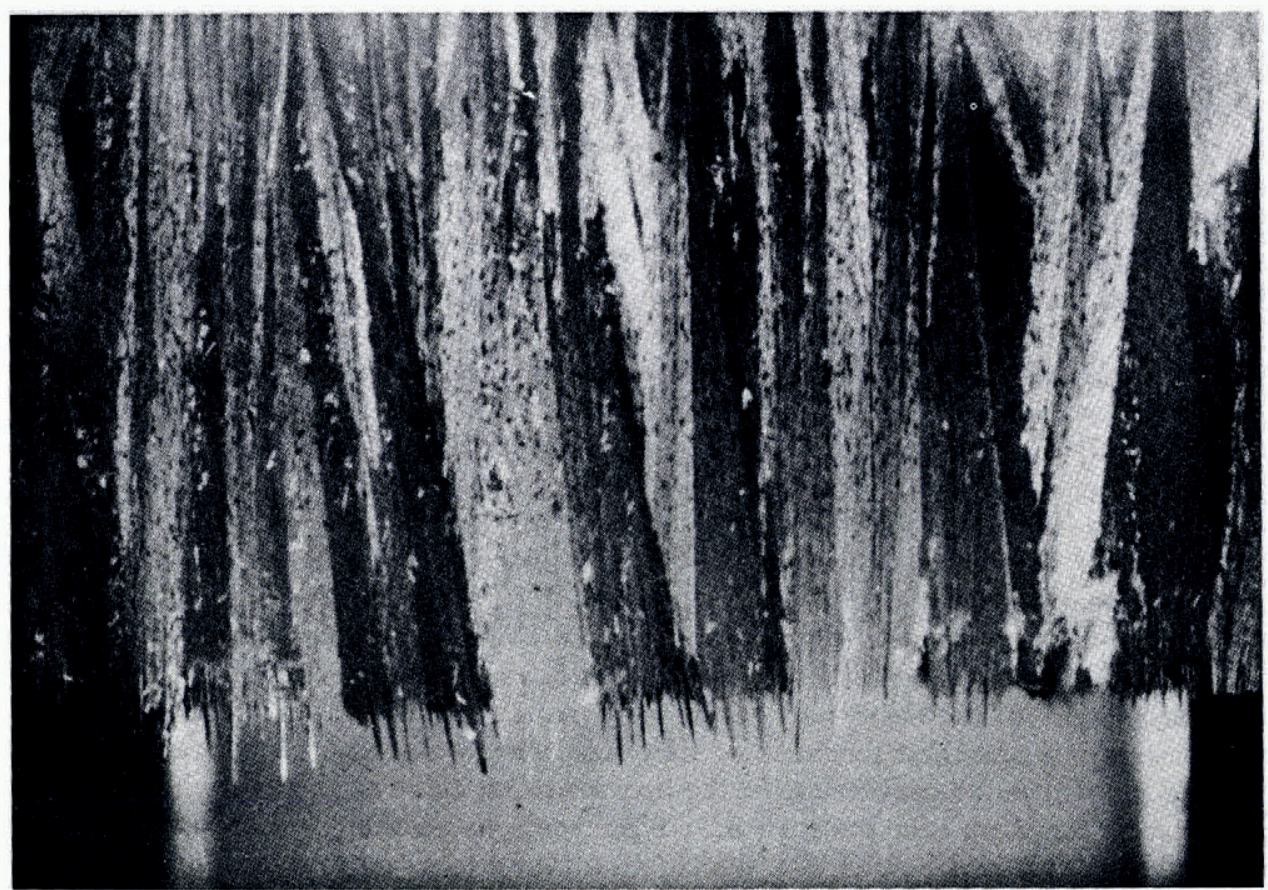

Fig. 2. A crossed-polaroid photograph of an ice sheet growing in our test cell. The thickness of the ice sheet from top to bottom is about $15 \mathrm{~cm}$.

On our crossed-polaroid photographs, however, the brine drainage channels are nearly invisible. To follow the growth and development of these channels, we used the $\mathrm{pH}$-sensitive dye "thymol blue" as a tracer in tv:o different ways. As Baker (1966) describes, when a $0.01 \%$ by weight solution of thymol blue in sea-water is made basic through the addition of a few drops of a one molar solution of $\mathrm{NaOH}$, the fluid turns dark blue. Similarly, addition of one or more drops of one molar $\mathrm{HCl}$ makes the solution acidic and the fluid color changes to light yellow. If a weak current flows between two electrodes placed in the acidic solution, a proton transfer takes place at the positive electrode with the result that the solution turns basic and therefore blue.

Therefore, inside our tank, we placed horizontal wires across our cell at $2 \mathrm{~cm}$ depth intervals, using platinum wire with a diameter of $10^{-1} \mathrm{~mm}$ as the positive electrode and equally thin copper wire as the negative. When current flowed between the wires, thin blue cylinders formed around the platinum wires. As Baker shows, since this dye technique, which involves only an electron transfer, does not change the local fluid density, the cylinders of dye follow the water motion until the color returns to yellow. An additional advantage of this technique is that the water beneath the ice could be quickly cleared of dye through the addition of a small amount of acid. Inside the ice, this technique worked well for the first day or two, but over the two-to-five day course of an experiment, gas bubbles formed on the 
wires and damaged the ice. Therefore, we supplemented this technique with the injection of a thymol blue solution into the bottom of the cell. The subsequent entrainment of the dyed water by the growing ice sheet also marked the drainage features.

\section{OBSERVATIONS OF THE BRINE DRAINAGE FEATURES}

The dye techniques yielded excellent pictures of the brine channels. As an example, Figure 3 is a sequence of three photographs in which we both injected dye under the ice and generated dye at the wires inside the ice. The figure shows that two different but related phenomena take place. First, there is a dye advance on a nearly uniform front up into the ice above the height of the interface at the time of dye injection. Second, there are concentrations of dye in "brine drainage channels" from which, especially in Figure $3 \mathrm{~b}$, entrained dye pours out of the ice.

We will first discuss the uniform entrainment of dye. Although they are not visible on the reproductions, a close examination of the original photographs of Figure 3 shows that the uniform upward flow of dye is accompanied by many small streamers leaving the ice similar to those observed by Foster (1969) and Farhadieh and Tankin (1972). Further, in a laboratory experiment on the absorption of oil by sea ice, Wolfe and Hoult (1974) observed that oil injected under growing sea ice was uniformly entrained. Therefore, our observations of this entrainment are consistent with other laboratory investigators.

Also, in their field observations of sea ice, LL observed that the ice near the ice-water interface consists of a porous dendritic crystal layer. They show photographs of closely-packed vertically-oriented tubes in this crystal layer, which they describe as right circular cylinders with constant radii of the order of $10^{-1} \mathrm{~mm}$. In addition to these visual observations, LL embedded thermistors in the lower part of the ice by allowing the sea ice to grow down over a thermistor array. From these thermistors, they observed regular variations in the temperature which they attributed to convection in the intergranular tubes near the ice-water interface. As the ice grew down past the thermistors, the fluctuations became smaller, then disappeared. Presumably, the upward flow of dye which we observe is visual evidence of the same convection.

For two cases, we measured the average height as a function of time of the upward entrainment of dye above the interface depth at the time of the dye injection. Figure 4 compares these measured points with a curve of the form

$$
z=a\left(\mathrm{r}-\mathrm{e}^{-b t}\right) \text {. }
$$

The open circles show the entrainment in the ice of Figure 3 ; the open triangles, entrainment in ice of an initial thickness $20 \mathrm{~cm}$, a case which may be affected by side-wall effects. For both cases, $b=7 \times 10^{-5} \mathrm{~s}^{-1}$, while for the first case, $a=\mathrm{I} .8 \mathrm{~cm}$, and the second, $a=5.75 \mathrm{~cm}$. At present, we have no theoretical model of this entrainment; however, it is presumably related to convection in the intergranular tubes.

The second obvious feature of Figure 3 is the presence and growth of the brine drainage channels. When we closely examined these channels within the cell, we found that they did not form preferentially against the "Plexiglas" walls, rather both the feeder and central channels meandered within the ice sheet. Many other investigators report the existence of brine channels; the best documentation is again that of LL. By cutting a large piece of natural sea ice into many horizontal sections, they obtained a three-dimensional picture of the brine drainage systems. They observed vertical channels with diameters of order of I $\mathrm{cm}$ extending at least $60 \mathrm{~cm}$ up into $1.6 \mathrm{~m}$ thick sea ice with a horizontal spacing of $10-20$ $\mathrm{cm}$. Each vertical channel had many slanted feeder tubes running into it, so that each system drained a cylindrical region with a diameter of the order of $10 \mathrm{~cm}$. As Figure 3 shows, the drainage channels which form in our ice sheet resemble on a much smaller scale those described by LL. 

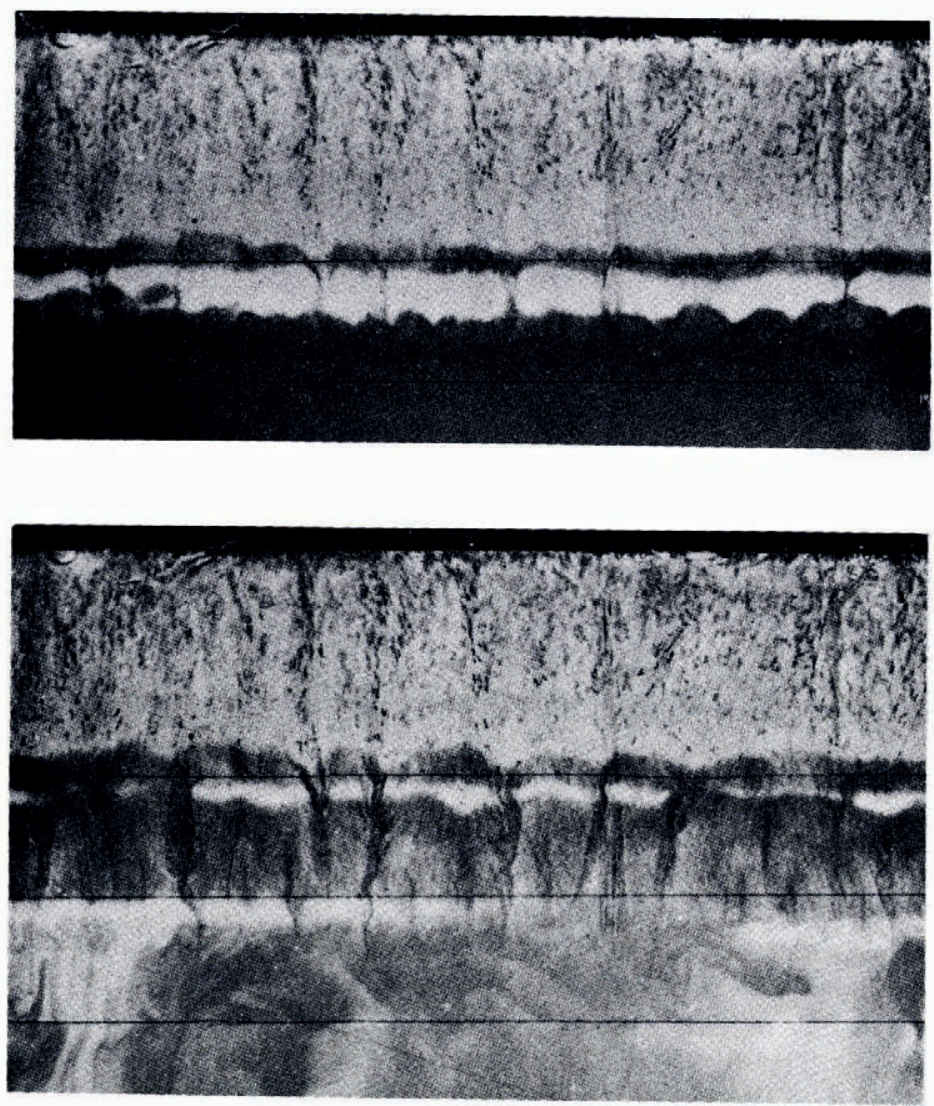

b

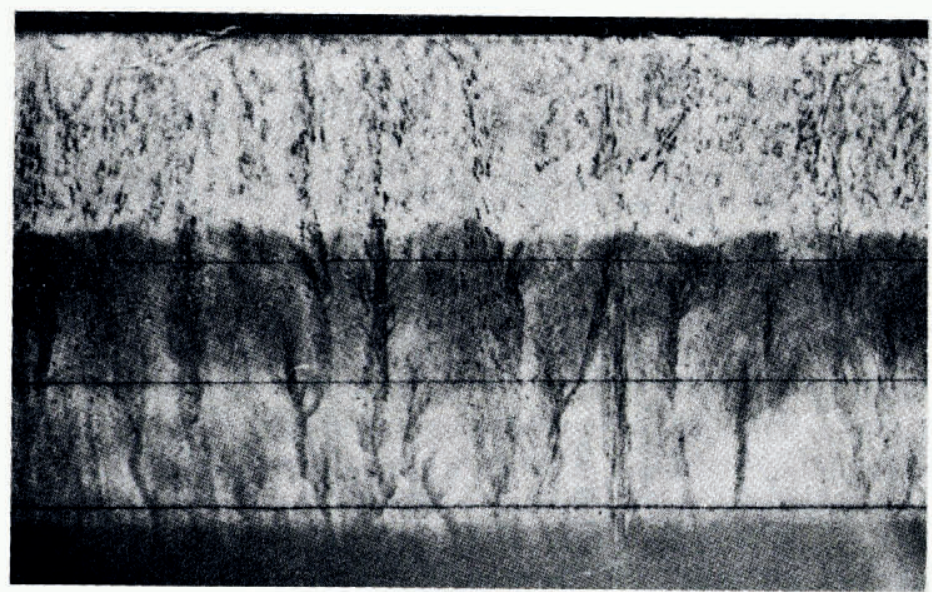

C

Fig. 3. A sequence of photographs illustrating the entrainment of dye and the formation of brine channels in our test cell. The horizontal wires are $2 \mathrm{~cm}$ apart. The dye was injected 170 min after the ice growth began. $(3 a) 188 \mathrm{~min} ;\left(3^{b}\right) 25^{8} \mathrm{~min}$; (3c) $3^{8} 4 \mathrm{~min}$. 


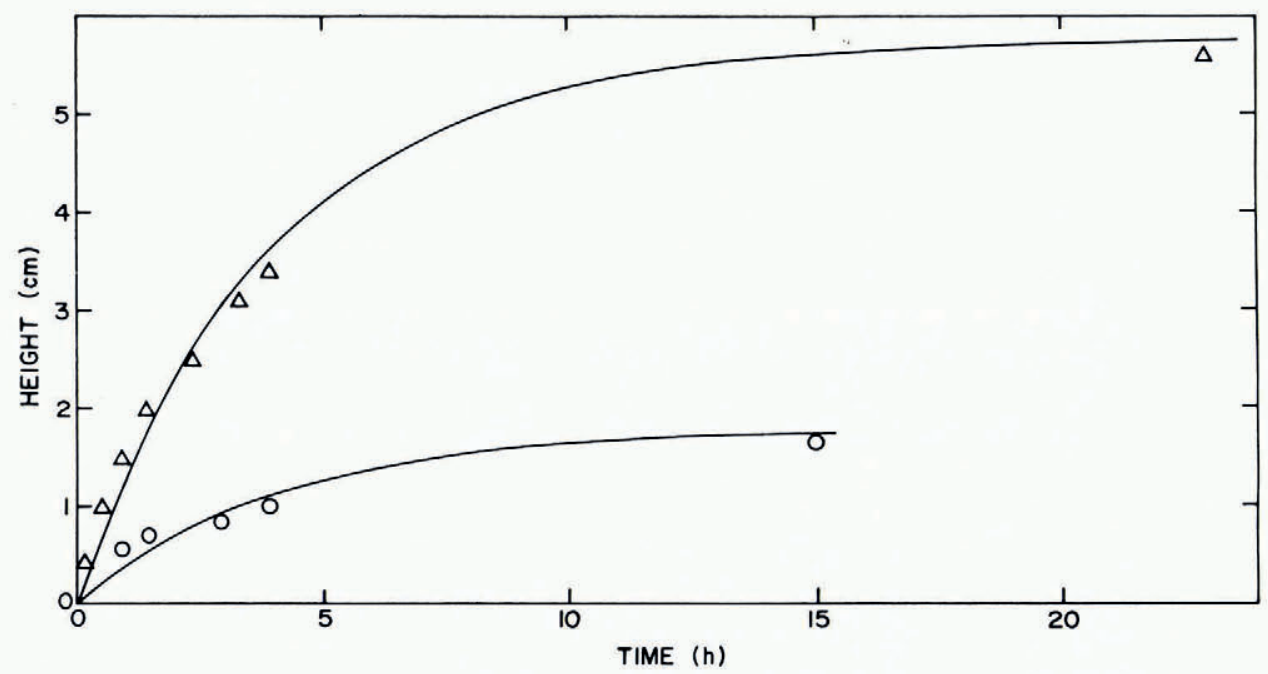

Fig. 4. The rise of dye into the ice above the interface height at the time of injection plotted against time. See text for additional discussion.

Figure 5 shows a close-up view of a brine drainage system similar to those in Figure 3 . The montage ( 5 a) clearly shows the brine channel, some of its feeder tubes, and the brine pouring out of the tip. The additional photograph of the tip $(5 \mathrm{~b})$ was taken roughly ro $\min$ after $(5 \mathrm{a})$. During this time, as the small arrow which marks the same pair of brine pockets in both photographs shows, the brine channel moved about $0.5 \mathrm{~cm}$ to the right. Comparison of $(5 \mathrm{a})$ and $(5 \mathrm{~b})$ shows that as the brine channel moved, it left a mass of randomly oriented ice crystals in its wake. The figure also shows what may be the original exit of the brine channel at about $0.25 \mathrm{~cm}$ to the left of the exit in Figure $5 \mathrm{a}$. Finally, an extremely interesting feature of the brine drainage channel is that the channel diameter just above the ice-water interface is about $\frac{1}{5}$ the diameter higher up in the ice. This brine channel "neck", which is a common feature of our laboratory ice, may also occur in natural sea ice. Careful examination of Figure 2 of LL, a photograph of a brine channel cross-section at the ice-water interface, suggests that just above the interface the channel diameter decreases from about $\mathrm{I} \mathrm{cm}$ to 2-3 $\mathrm{mm}$.

Our time-lapse films, even though the individual frames are of insufficient quality for journal reproduction, provide additional information about the formation and evolution of these brine channels. First, on these films the feeder channels appear suddenly from the apparent fracture of both air and brine pockets into a central channel. Second, as in Figure 5, the channel tips sway and move across the crystals with time. Third, in a large number of cases oscillations consisting of a brine flow out of the icc, followed by a sea-water flow up into the ice, occur in the brine channels. For example, in $10 \mathrm{~cm}$ thick ice, we observed in one instance a total of 8-10 individual brine drainage systems over a horizontal distance of about $20 \mathrm{~cm}$. Oscillations occurred in each of these channels, with the duration of the downward flow being generally much longer than that of the upward flow. The most regular of these oscillators, which we followed for $8 \mathrm{~h}$, had a period of roughly $\mathrm{I}$ h, with an 8-I 5 min inflow and an approximately $45 \mathrm{~min}$ outflow.

In the following sections, we first present a qualitative model for the formation of brine drainage systems, then give a physical explanation for the brine-channel neck, and finally show that the neck may be the cause of the observed oscillations. 


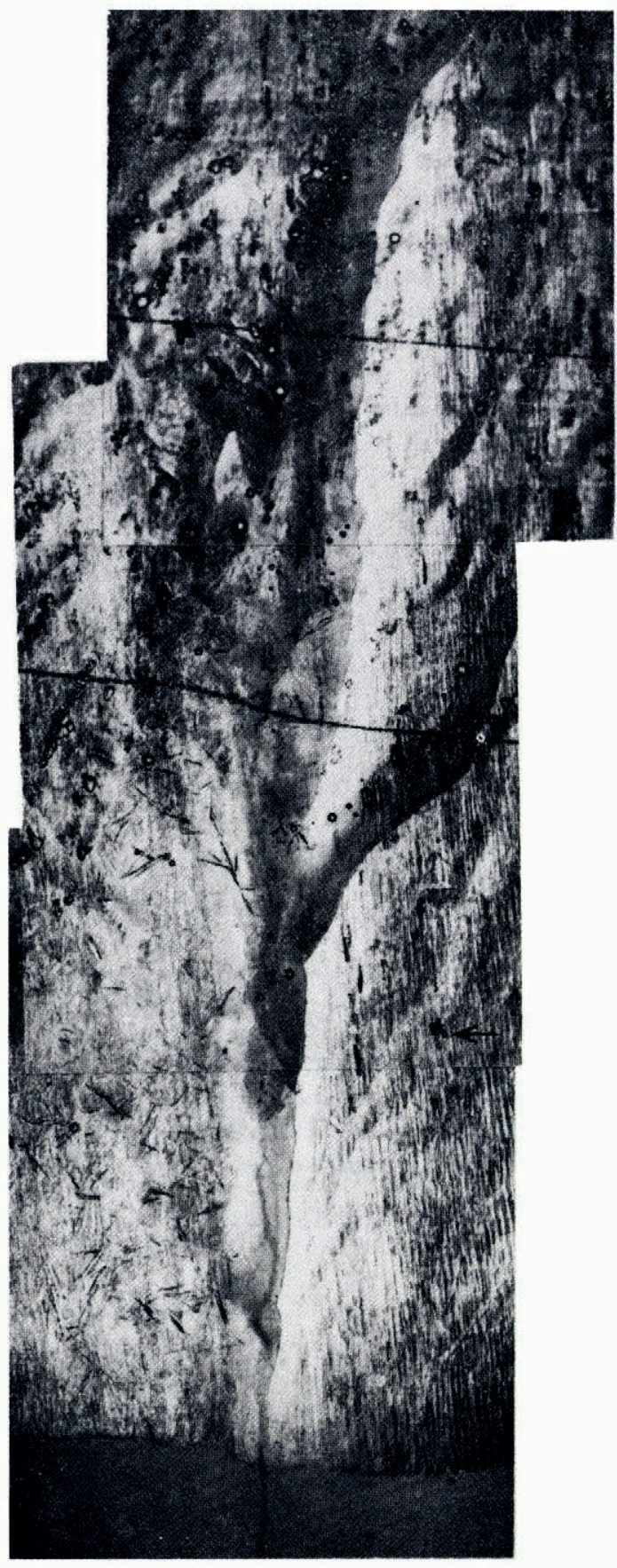

a

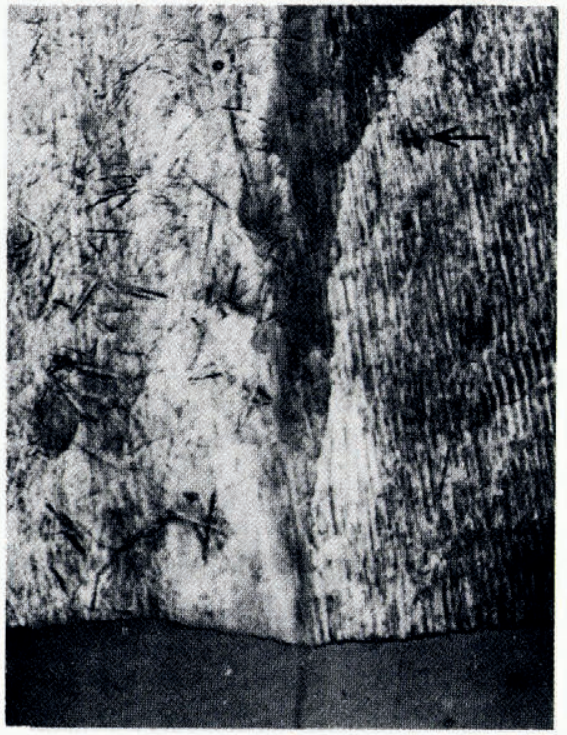

b

Fig. 5. A close-up photograph of a brine drainage system. ( $5 b)$ was taken roughly ten minutes after (5a). The lack of clarity of the tip in $(5 b)$ is caused by crystals being between the camera and the channel. 


\section{The FORMATION OF BRINE DRAINAGE GHANNELS IN YOUNG SEA ICE}

We base our qualitative, physical model for the formation of brine channels in young, growing sea ice on the studies of $\mathrm{R}$ and $\mathrm{S}$, who describe the formation of drainage tubes in temperate glaciers from the movement of water through the porous ice. In our model, we assume that the sea ice is sufficiently warmer than $-23^{\circ} \mathrm{C}$ so that it also is porous. The best evidence for the porosity of sea ice are the previously cited observations of the absence of salt above the water-line. This suggests that the difference between the hydrostatic head of seawater and that of the interior brine creates the pressure gradient force which drives the brine out of the ice. As R and S show for temperate glaciers, the difference between the pressure head of the ice and that of the fresh water generates an analogous driving force.

To calculate the force driving the brine out of the ice, we consider a growing ice sheet which is permeated with brine channels, floating in sea-water. From Figure 6, a schematic view of the ice sheet, the sea-water hydrostatic pressure at a height $z$ below the water-line inside the ice is

$$
p=\rho_{0} g\left\{H_{\mathrm{I}}(t)-z\right\}
$$

where $\rho_{0}=1.025 \mathrm{Mg} \mathrm{m}^{-3}$ is the sea-water density, $g=9.8 \mathrm{~m} \mathrm{~s}^{-2}$ is the acceleration of gravity, and $H_{1}(t)$ is the depth to which the ice sheet is submerged.

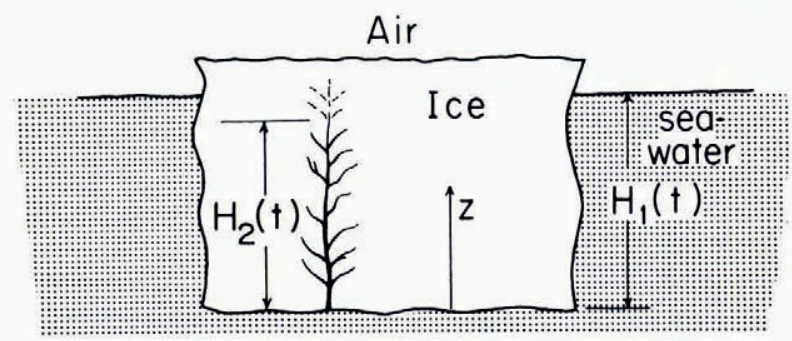

Fig. 6. The co-ordinate system used in the discussion of brine channel formation. $H_{1}(t)$ is the depth to which the ice sheet floats, and $\mathrm{H}_{2}(t)$ is the height of brine in a brine drainage channel.

To calculate the pressure in a brine channel, we note that in a growing ice sheet, the temperature generally decreases upward from the bottom of the ice. For the brine inside the ice to be in equilibrium with the ice at each level, the salinity $s$ and thereby the brine density $\rho_{\mathrm{b}}$ must also increase with height. Therefore, the brine hydrostatic pressure $p_{\mathrm{b}}$ inside of a channel is

$$
p_{\mathrm{b}}(z)=g \int_{z}^{H_{2}(t)} \rho_{\mathrm{b}}(T(z)) \mathrm{d} z
$$

where $H_{2}(t)$, the level of the brine in the channel system, may be greater than $H_{\mathrm{I}}(t)$.

In our experiment, the ice begins its growth as a matrix of vertical dendrites and intergranular tubes. In the field, sea ice begins as a thin layer of horizontal crystals, after which the growth resembles our laboratory ice. Therefore, to model the formation of a brine drainage system, we consider the steady Poisseuille flow of brine in a tube of uniform radius $r$ extending vertically up into the ice. From simple hydraulics theory (see Röthlisberger (1972) or Martin (1970) for the derivation and additional references) with the addition of the Boussinesq approximation, which neglects variations in density except when they occur in product with $g$, the volume flux $q$ out of the tube is

$$
q=\frac{\pi r^{4}}{8 \bar{\rho}_{\mathrm{b}} \bar{\nu}_{\mathrm{b}} H_{2}(t)} \Phi(t),
$$


where

$$
\Phi(t)=p_{\mathrm{b}}(\mathrm{o})-p(\mathrm{o})
$$

and $\bar{\rho}_{\mathrm{b}}$ and $\bar{\nu}_{\mathrm{b}}$ are respectively the mean density and viscosity of the brine. When $\Phi(t)=0$, there is no volume flux from the tube. Further, for a particular density gradient, the solution of $\Phi(t)=0$ gives the minimum value of $H_{2}$ in terms of $H_{1}$.

Given Equation (7), we next show for a linear temperature gradient inside the ice, that, as the ice thickness increases, brine flows out of the ice. For a linear profile, we write the temperature difference across the ice sheet as

$$
\theta=\frac{T_{0}-T_{\mathrm{m}}}{H_{\mathrm{I}}(t) \rho_{\mathrm{o}} / \rho_{\mathrm{I}}} z,
$$

where $T_{0}$ is the sea-water temperature, $T_{\mathrm{m}}$ the assumed constant temperature of the upper surface, and the denominator is the total ice thickness.

On the additional assumption that the density of the brine inside the ice is a linear function of $\theta$, we write

$$
\rho_{\mathrm{b}}=\rho_{0}(\mathrm{I}+\gamma \theta) \text {. }
$$

Since $\rho_{\mathrm{b}}$ varies from $\mathrm{I}$.o $\mathrm{Mg} \mathrm{m}^{-3}$ at $\mathrm{O}^{\circ} \mathrm{C}$ to $1.2 \mathrm{Mg} \mathrm{m}^{-3}$ at $-20^{\circ} \mathrm{C}$, the value of the parameter is $\gamma \approx 10^{-2} \mathrm{deg}^{-1}$.

Given Equations (9) and (7), we can solve for the minimum level of $\mathrm{H}_{2}$ as a function of $H_{1}$ as the ice thickness increases. Substitution of Equation (9) into Equation ( $7 \mathrm{~b}$ ) and solution for $\mathrm{H}_{2}$ gives

$$
\frac{H_{2}}{H_{1}}=\frac{1}{\beta}\left[(\mathrm{I}+2 \beta)^{1}-\mathrm{I}\right],
$$

where

$$
\beta=\frac{\rho_{\mathrm{i}}\left(T_{0}-T_{\mathrm{m}}\right) \gamma}{\rho_{0}}
$$

For $T_{\mathrm{o}}-T_{\mathrm{m}}=15^{\circ} \mathrm{C}, \beta \approx 10^{-1}$. Since $\beta \ll \mathrm{I}$, we write Equation (10) as

$$
\frac{H_{2}}{H_{1}} \approx \mathrm{I}-\frac{\beta}{2}<\mathrm{I} \text {. }
$$

From Equation (I I), as the ice thickness increases, the equilibrium brine level relative to the free surface decreases. Therefore, as the ice grows thicker, the pressure-gradient force drives the cold brine in the small intergranular tubes down into warmer ice.

The downward movement of cold brine generates a heat flux to the tube. The flux has two components; first, the heat flux $F_{\mathrm{t}}$ generated by the temperature difference between the brine and its surroundings; second, the heat flux $F_{\mathrm{s}}$ generated by the side-wall melting which occurs to keep the brine on the eutectic curve. In the Appendix, we show that the ratio $\alpha$ of these two fluxes for the idealized case of a small volume of fluid of salinity $s$ subjected to a small temperature change $\Delta T$ is

$$
\alpha=\frac{F_{\mathrm{s}}}{F_{\mathrm{t}}} \approx \frac{7.4 \times 10^{2}}{s} .
$$

For $s=200 \%, \alpha=4$; for $s=35 \%, \alpha=2 \mathrm{I}$. From Equation (12), the melting generated by the eutectic boundary condition creates a much larger heat flux than that caused by the warming of the cold brine.

The combination of the side-wall melting and the large heat flux to the tube has two effects. First, the large heat flux cools the adjacent ice and thus creates a cold region around the tube. Through the eutectic condition, this cooling increases the brine density in Equation (6), so that the pressure-gradient force driving the brine out of the ice also increases. Second, the side wall melting increases the tube radius $r$ in Equation (7a). Since $q \propto r^{4}$, a small 
increase in radius yields a much faster flow of brine out of the tube, which thereby decreases the brine pressure head. Therefore, the combined effects of the side-wall melting generate a cold, low-pressure region around a brine tube. This forces the brine in the surrounding ice to flow to the region of lower pressure at the tube, or alternatively to fracture through to the tube and thereby generate the feeder channels. In particular, the cooling of the surrounding ice may cause the fracture of the nearby brine pockets from the freezing-generated pressure build-up; this process may yield the sudden formation of feeder channels which we observe in our time-lapse films.

Obviously if all of the intergranular tubes are of the same initial diameter, the above process will not generate the brine drainage systems, since the diameter of each intergranular tube will grow at the same rate. In reality, small variations in both tube diameter and pressure head cause some tubes to grow faster than others, thereby yielding the observed drainage systems. Thus salinity plays a similar role in enlarging the size of drainage channels to that turbulent heating plays in the glacier models of $\mathrm{R}$ and $\mathrm{S}$.

\section{THE "NECK" PHENOMENON IN BRINE DRAINAGE GHANNELS}

Because the sea-water under growing sea ice is at its freezing point, there is one major difference between sea-ice and glacier drainage. To illustrate, Figure 7 compares schematic drawings of the drainage systems for temperate glaciers and sea ice. The glacier drainage follows the descriptions of $\mathrm{R}$ and $\mathrm{S}$; the sea-ice drainage is based both on our Figures 3 and 5 and the field observations of LL. The glacier drainage system is "arboreal" or river-like, with the channel radii increasing toward the exit. The sea-ice drainage system is nonarboreal, in that the channel has a neck just above the ice-water interface. This neck, which we next show to be a real physical phenomenon, may be the cause of the oscillations observed in our films.

For most of our observed brine drainage systems, the radius of the bottom few millimeters of a channel is much less than the channel radius inside the ice. Martin (1974, abbreviated MS) shows that a similar neck occurs at the tip of a growing ice stalactite, in that the inner radius of the stalactite tip through which brine exits to the sea-water is much smaller than

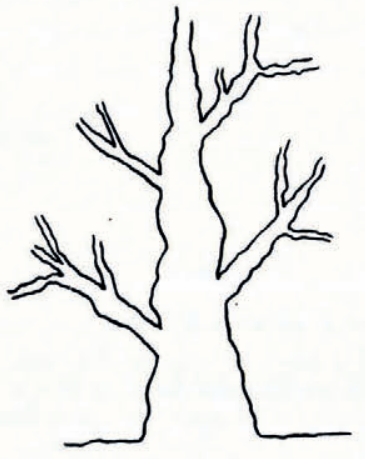

a

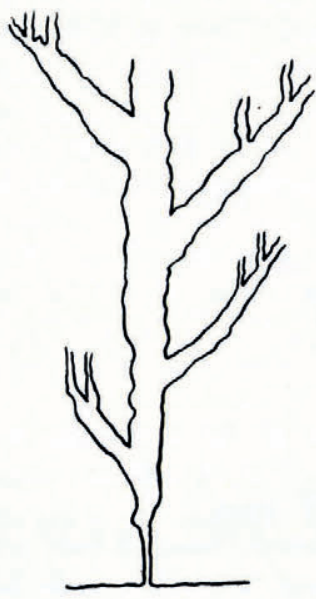

b

Fig. 7. A comparison of the drainage systems for (a) temperate glaciers and $(b)$ young sea ice. See text for additional discussion. 
the stalactite inner radius away from the tip. From both a scale analysis and direct observation, MS shows that the onset of a convective instability maintains the small tip size. In the following, we argue that the same instability controls the exit radius of a brine channel.

Two factors determine the small size of both the stalactite tips and the brine-channel necks. In each case, the sea-water under growing ice is both at its salinity-determined freezing point and lighter than the brine which flows from the ice. The effect of the density difference $\Delta \rho$ between the sea-water and the brine is to create a buoyancy force $\Delta \rho g$ acting upward. Inside either the stalactite or channel, a pressure gradient force $F_{\mathrm{p}}$ which drives the brine out of the ice opposes this buoyancy force.

To calculate $F_{\mathrm{p}}$, we assume for simplicity that both the magnitude of the volume flux $q$ in the neck is imposed on the neck by the properties of the upper part of the drainage channel and the flow in the neck is Poisseuille flow, in which case

$$
F_{\mathrm{p}}=\frac{8 \rho_{\mathrm{b}} \nu_{\mathrm{b}} q}{\pi a^{4}}
$$

where $a$ is the radius of the neck. From Equation (1 13$)$, for a sufficiently small neck radius, $F_{\mathrm{p}}>\Delta \rho g$, and the brine flows out of the neck in a uniform stream; for a larger neck radius, $F_{\mathrm{p}}<\Delta \rho g$, so that the buoyant sea-water intrudes into the neck. Then, because the sea-water is at its freezing point and the ice is colder than the water, some of the sea-water freezes to the side of the neck. The intrusion and freezing continue until the radius $a$ is reduced to the point where the forces balance.

Because the salinity-driven ablation always acts to increase the neck radius, while the intrusion and freezing of sea-water decreases the radius, the value of $a$ should be determined by the force balance $F_{\mathrm{p}}=\Delta \rho g$. MS calls the ratio of these two forces an "entrainment" number $E$, where

$$
E=\frac{\pi}{8} \frac{\Delta \rho g a^{4}}{\rho_{\mathrm{b}} \nu_{\mathrm{b}} q} .
$$

When $E<\mathrm{I}$, the flow from the neck is unidirectional; when $E>\mathrm{I}$, overturning occurs. For stalactite tips, MS shows that the tip radius is very nearly predicted by $E=\mathrm{I}$.

Given the above argument, Figure 8 shows how the neck adjusts to a change in flow rate. In Figure 8a, the brine flows uniformly out of the tip. In Figure $8 \mathrm{~b}$, we abruptly decrease the flow so that $E>\mathrm{I}$. Therefore as Figure $8 \mathrm{c}$ shows, sea-water intrudes into the neck, freezes to the wall, and reduces the radius back to a sub-critical value. Because of the difficulties of measuring volume flow rates from brine channels, we have not quantitatively compared the observed values of $a$ with the values computed from $E=\mathrm{I}$; however, we have qualitatively observed in our experiments that $a$ decreases smoothly as $q$ decreases.

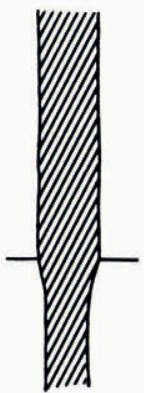

a

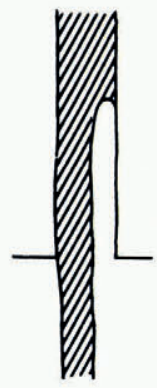

b

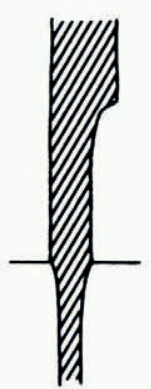

C Fig. 8. The sequence of sketches $(a-c)$ shows how the tip of a brine channel adjusts to a decrease in flow rate. In the sketches,
the dark brine flows out of the ice into sea-water. 
For very slow flows, or in the limit of $q \rightarrow 0$, salt diffusion becomes important so that the above criterion is no longer valid. For $q=0, \mathrm{LL}$ argue that a Rayleigh-number criterion determines the minimum size of a channel. Using this criterion (see LL for references), they show that the minimum tube size is determined from

$$
\frac{g a^{4}}{\rho D \nu} \frac{\partial \rho}{\partial z} \approx 68,
$$

where $\partial \rho / \partial z$ is the density gradient inside the tube imposed by the temperature field in the ice, and $D$ is the salt diffusivity.

For our experiment, the temperature gradient is of order $\mathrm{IO}^{2} \mathrm{deg} \mathrm{m}^{-1}$, so that $(\mathrm{I} / \rho)(\partial \rho / \partial z) \approx \mathrm{I} \mathrm{m}^{-1}$ and $D \approx \mathrm{I}^{-9} \mathrm{~m}^{2} \mathrm{~s}^{-1}$. Substitution of both these values and the other parameters into Equation (15) gives a minimum channel size of $a=3 \times 10^{-1} \mathrm{~mm}$, which is of the observed order. Therefore in the limit of $q \rightarrow 0$, the channel remains open.

\section{Oscillations In THE BRine GHANNELS}

A theoretical consequence of both the presence of the neck and the gravity drainage from the channel is that oscillations similar to those observed in our time-lapse films can occur in the brine channels. Martin (1970, hereafter abbreviated as MSO) observed and theoretically described similar oscillations in a hypodermic syringe. In the following, we will first discuss the similarities between a brine channel and a syringe, then physically describe why the oscillations occur.

A syringe which is filled with brine and partially submerged in a beaker of fresh water is a crude approximation to a brine channel. The thin needle of the syringe is analogous to the neck of the channel, while the broad barrel crudely models the brine-channel-feeder-tube system above the neck. The open top of the syringe, which could be replaced by a porous plug without affecting the oscillations, models the ice porosity. As Figure 9 shows, the oscillations in a syringe occur as a downward jet of brine, followed by an upward jet of water, and so on for many cycles. It is very easy to produce these oscillations in the laboratory. In his experiments, MSO measured periods varying from $4 \mathrm{~s}$ to several minutes, depending on the particular choice of needle and syringe. The length of the needle can be very short without eliminating the oscillations; in one case MSO (p. 143) observed that "a tin can of radius $3.3 \mathrm{~cm}$ with a pin hole in the bottom, which was initially filled to a depth of $8 \mathrm{~cm}$ with a saturated solution of sodium chloride produced oscillations with a period of $40 \mathrm{~s}$ and ran for four days".

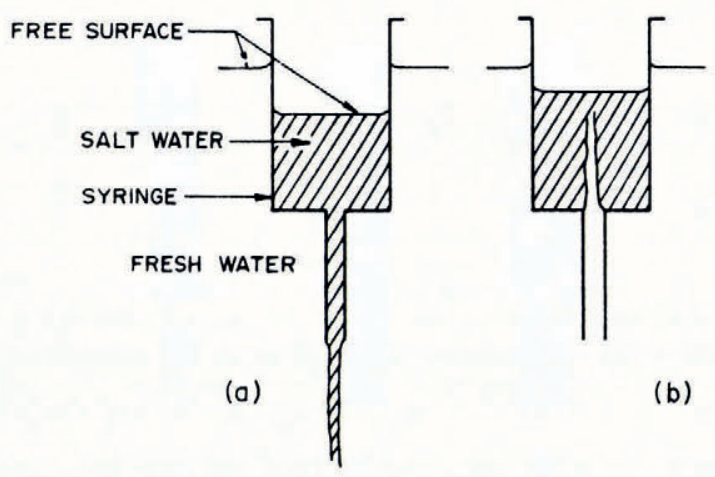

Fig. 9. The oscillations in a brine-filled syringe. (a) Downward flow. (b) Upward flow. (Adapted from Martin (1970), figure 1 ). 
The reason the oscillations occur is that the brine level inside the syringe oscillates between two positions of hydrostatic equilibrium. As Figure ro shows, the equilibrium brine level inside the syringe is lower when brine fills the needle than when fresh water fills the needle. Suppose the system is initially at position (a) in Figure ro with the needle filled with brine. Then, any diffusive or convective exchange process in the bottom of the needle which replaces the brine with fresh water disturbs the hydrostatic balance, since the fresh water interface moves up the needle while the brine level inside the syringe is unchanged.

For the fluid to remain in hydrostatic equilibrium, the brine interface in the syringe must rise by a height proportional to that of the fresh water intrusion in the needle. Because the cross-sectional area of the syringe is much greater than that of the needle, restoration of equilibrium requires the flow of a relatively large volume of water into the syringe. Therefore, a small mass perturbation in the needle creates a large pressure imbalance in the syringe which then amplifies the perturbation and accelerates fresh water up the needle until a jet erupts into the syringe. The upward flow continues until the interface level in the syringe reaches the second hydrostatic position in Figure rob with fresh water filling the needle. At this point, the process is reversed, in that any movement of brine into the needle again creates a pressure imbalance which now accelerates brine down the needle, thus generating a downward jet. In this way, the oscillations continue until the fluid in the syringe is diluted almost to the fresh-water density.

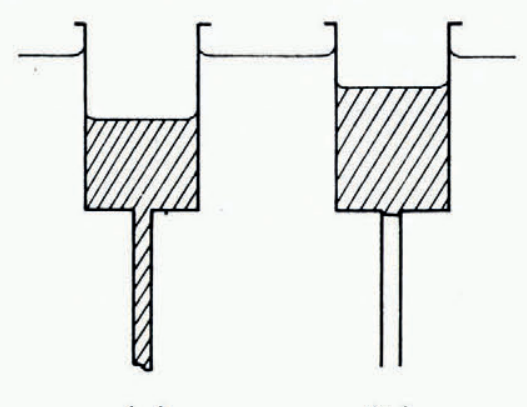

(a)

(b)

Fig. so. The positions of hydrostatic balance in the syringe. (a) Needle filled with salt water. (b) Needle filled with fresh water (adapted from Martin (1970), figure 3).

There are several differences between the syringe and the brine channels. First, an ice neck replaces the needle, where the entrainment number criterion controls the radius of the neck for the downward flow. This variation of the needle radius with volume flux changes the theory described in MSO, but does not alter the physics. Second, the ice is growing, which is equivalent to slowly submerging the syringe without changing the mean brine level. This means that the upward and downward jets will not have equal periods, rather the flow will be primarily downward with brief periods of upward flow. This inequality of the upward and downward periods is what we observe in our time-lapse films. Third, the syringe model completely neglects any temperature effects such as the freezing of sea-water inside the ice with the subsequent change in volume. In spite of this neglect, the effects of the geometry of the brine channel should be more important than the interior freezing and melting in governing the onset of the oscillations. In conclusion, the syringe analogy strongly suggests that the brine channel geometry causes the observed oscillations. 


\section{ConGLuding REMARKS}

If the oscillations observed in our laboratory ice also occur in the pack ice, they would serve as efficient rapidly-acting pumps for the removal of brine from ice and its replacement with sea-water. Besides providing an efficient desalination mechanism, the oscillations may have three additional effects. First, they would provide both oxygen and nutrients to organisms living inside the ice. Second, the oscillations would contribute to the liquid content of the lower part of the ice, a factor which is important in the absorption and reflection of underwater sound. Third, the oscillations would entrain pollutants, such as petroleum or pesticides, inside the growing ice. For example, this entrainment could absorb and store part of a winter oil spill for later release during the summer melting. Both the oscillatory pumping and the overall entrainment process described in the second section and observed by Wolfe and Hoult (1974) for oil released under ice could be important in planning for the control of oil spills in ice-covered seas.

\section{Acknowledgements}

The authors thank both Donald Immerwahr and Peter Kauffman for their helpful suggestions and assistance with the experiment; and specifically Peter Kauffman for photographing the brine channel shown in Figure 5 and printing all of the photographs shown herein. We also thank Arnold Weickert for his skillful craftsmanship in building the experimental tank, and acknowledge that the design of our tank was suggested by Dr Ruby Krishnamurti's experiments at Florida State University on the production of thermally-driven turbulent convection inside a Hele-Shaw cell. Finally, we gratefully acknowledge the support of the Office of Naval Research through Project No. NR $307-25^{2}$ and Contract No. Nooo1467-A-0103-0007.

\section{MS. received 14 March 1974 and in revised form 10 . June 1974}

\section{REFERENCES}

Baker, D. J. 1966. A technique for precise measurements of small fluid velocities. Journal of Fluid Mechanics, Vol. 20, No. 3, p. 673-75.

Bennington, K. O. 1963 . Some crystal growth features of sea ice. Journal of Glaciology, Vol. 4, No. 36, p. 669-88. Bennington, K. O. 1967. Desalination features in natural sea ice. Journal of Glaciology, Vol. 6, No. 48, p. 845-57. Carslaw, H. S., and Jaeger, J. C. 1959. Conduction of heat in solids. Second edition. Oxford, Clarendon Press.

Cox, G. F. N., and Weeks, W. F. 1974. Salinity variations in sea ice. Journal of Glaciology, Vol. 13, No. 67, p. $109-20$.

Farhadieh, R., and Tankin, R. S. 1972. Interferometric study of freezing of sea water. Journal of Geophysical Research, Vol. 77, No. 9, p. $1647-57$.

Foster, T. D. 1969 . Experiments on haline convection induced by the freezing of sea water. Journal of Geophysical Research, Vol. 74, No. 28, p. 6967-74.

Grober, H., and others. $196 \mathrm{1}$. Fundamentals of heat transfer, by H. Grober, S. Erk and U. Grigull. New York, McGrawHill Book Co., Inc.

Hodgeman, C. D., ed. 1955. Handbook of chemistry and physics. Thirty-seventh edition. Cleveland, Ohio, Chemical Rubber Publishing Co.

Kaufman, D. W., ed. 1960. Sodium chloride. New York, Reinhold Publishing Corp.

Lake, R. A., and Lewis, E. L. 1970. Salt rejection by sea ice during growth. Journal of Geophysical Research, Vol. 75 , No. 3, p. $5^{8} 3-97$.

Lofgren, G., and Weeks, W. F. 1969. Effect of growth parameters on substructure spacing in $\mathrm{NaCl}$ ice crystals. Journal of Glaciology, Vol. 8, No. 52, p. $153-64$.

Malmgren, F. 1927. On the properties of sea ice. The Norwegian North Polar Expedition with the "Maud" $1918-1925$. Scientific Results, Vol. I, No. 5 .

Martin, S. 1970. A hydrodynamic curiosity: the salt oscillator. Geophysical Fluid Dynamics, Vol. 1, p. 143-6o.

Martin, S. 1974. Ice stalactites: comparison of a laminar flow theory with experiment. Fournal of Fluid Mechanics, Vol. 63 , Pt. 1, p. 51-86. 
Ono, N. 1967. Specific heat and heat of fusion of sea ice. (In Oura, H., ed. Physics of snow and ice: international conference on low temperature science. ... I966. . . Proceedings, Vol. I, Pt. I. [Sapporo], Institute of Low Temperature Science, Hokkaido University, p. 599-6ro.)

Perry, R. H., and others, ed. 1963. Chemical engineers' handbook, edited by R. H. Perry, C. H. Chilton and S. D. Kirkpatrick. New York, McGraw-Hill Book Co., Inc.

Röthlisberger, H. 1972. Water pressure in intra- and subglacial channels. Journal of Glaciology, Vol. 11, No. 62, p. $177-203$.

Shreve, R. L. 1972. Movement of water in glaciers. Journal of Glaciology, Vol.. I I, No. 62, p. 205-14.

Untersteiner, N. 1967 . Natural desalination and equilibrium salinity profile of old sea ice. (In Oura, H., ed. Physics of snow and ice: international conference on low temperature science. . . . 1966. . . Proceedings, Vol. I, Pt. I. [Sapporo], Institute of Low Temperature Science, Hokkaido University, p. 569-77.)

Weeks, W. F., and Lee, O. S. 1962. The salinity distribution in young sea ice. Arctic, Vol. 15, No. 2, p. 92-ro8.

Whitman, W. G. 1926. Elimination of salt from sea-water ice. American Journal of Science, Vol. 211, No. 62 , p. $126-32$.

Wolfe, L. S., and Hoult, D. P. 1974. Effects of oil under sea ice. Journal of Glacislogy, Vol. 13, No. 69, p. 473-88.

\section{APPENDIX}

\section{The Thermal consequences of brine movement inside the ICE}

When brine which is initially in equilibrium with the surrounding ice walls moves into warmer ice, heat flows to the brine. This heat flow has two components. First, the temperature difference between the brine and the surrounding ice generates a "thermal" flow $Q_{t}$; second, the melting of the ice generated by the eutectic boundary condition generates a "saline" flow $Q_{\mathrm{s}}$.

To model the kinematics of this phenomenon, w 2 consider a volume element of salt water at a temperature $T_{0}$, salinity $s_{0}$, and with a density $\rho_{0}$ and volume $V_{0}$ which is in equilibrium with a much larger volume of ice at $T_{0}$. We then increase the ice temperature to $T_{0}+\Delta T$. To calculate the total heat flow to the brine element, we assume the element first warms to the temperature $T_{0}+\Delta T$, then the walls melt to keep the brine on the eutectic curve. Ono (1967) and other investigators made calculations similar to the following in the derivations of the latent and specific heats of sea ice. In the present calculations, however, we wish to examine the dynamic consequences of this heat flow.

Given a temperature change $\Delta T$, the heat flow to the volume element is

$$
Q_{\mathrm{t}}=\rho_{0} c_{p} \Delta T V_{0},
$$

where $c_{p}$ is the specific heat capacity. To dilute the brine so that it remains on the eutectic curve, the volume increases by an amount $\Delta V$, thus generating the additional heat flow

$$
\dot{Q}_{\mathrm{s}}=L \rho_{\mathrm{i}} \Delta V \text {, }
$$

where $L$ is the latent heat and $\rho_{1}$ is the ice density

To compare the magnitude of $Q_{\mathrm{s}}$ with $Q_{\mathrm{t}}$, we write $\Delta V$ in Equation ( $16 \mathrm{~b}$ ) in terms of $T_{0}$ and $\Delta T$ from the conservation of salt. For the brine element, the conservation of salt may be written as

$$
\frac{\partial}{\partial T}(s \rho V)=0 .
$$

Differentiation of Equation ( 17 ) along the eutectic curve gives

$$
\left.s \rho \frac{\partial V}{\partial T}\right|_{\mathbf{E}}+\left.\rho V \frac{\partial s}{\partial T}\right|_{\mathbf{E}}+\left.V s \frac{\partial \rho}{\partial T}\right|_{\mathbf{E}}=0,
$$

where the subscript $\mathrm{E}$ refers to the eutectic curve.

For sodium chloride solutions, or sea-water above $-23^{\circ} \mathrm{C}$,

$$
-\left.\frac{\partial s}{\partial T}\right|_{\mathbf{E}}=m_{\mathrm{I}} \approx 10 \% \mathrm{deg}^{-1},
$$

and

$$
m_{2}=-\left.\frac{\partial \rho}{\partial T}\right|_{\mathrm{E}} \approx \mathrm{10}^{-2} \mathrm{Mg} \mathrm{m}^{-3} \mathrm{deg}^{-1},
$$

where $m_{1}$ and $m_{2}$ are approximately constant.

From Equation (19), we rewrite Equation (18) as

$$
\left.\frac{\mathbf{I}}{V} \frac{\partial V}{\partial T}\right|_{\mathbf{E}}=\frac{m_{1}}{s}+\frac{m_{2}}{\rho} .
$$


In sea ice, the salinity $s$ varies from approximately $30-230 \%$ and the brine density $\rho \approx 1 \mathrm{Mg} \mathrm{m}^{-3}$, so that

$$
\frac{m_{1}}{s} \approx 3 \times 10^{-1}-3 \times 10^{-2}>\frac{m_{2}}{\rho} \approx 10^{-2} .
$$

Therefore, as a fair approximation, Equation (20) in difference form becomes

$$
\frac{\Delta V}{V_{0}} \approx \frac{\Delta T m_{1}}{s_{0}}
$$

where we assume $\Delta V$ and $\Delta T$ vary along the eutectic curve.

Substitution of Equation (2I) into Equation ( $16 \mathrm{~b})$ gives

$$
Q_{\mathrm{s}}=\frac{L_{\rho_{1}} V_{0} \Delta T m_{\mathrm{I}}}{s_{0}}
$$

so that the ratio of the two heat flows become

$$
\frac{Q_{\mathrm{s}}}{Q_{\mathrm{t}}}=\alpha=\frac{L \rho_{1} m_{\mathrm{I}}}{\rho c_{p} s_{0}} .
$$

Since the heat flux is defined as the heat flow per unit time, $\alpha$ is also the ratio of the respective heat fluxes.

For sodium chloride solutions, $L=335 \mathrm{~kJ} \mathrm{~kg}^{-1}, \rho_{1}=0.92 \mathrm{Mg} \mathrm{m}^{-3}, \rho \approx \mathrm{I} . \mathrm{I} \mathrm{Mg} \mathrm{m} \mathrm{Mg}^{-3}$, and $c_{p}=3.8 \mathrm{~kJ} \mathrm{~kg}^{-1}$ $\mathrm{deg}^{-1}$ (from Kaufman, 1960). Substitution of these values into Equation (23) gives

$$
\alpha=\frac{740}{s_{0}} .
$$

Therefore, $\alpha$ varies from 4 at $s=200 \%$ to 21 at $s=35 \%$, so that the movement and subsequent dilution of brine within the ice may yield a large flux of heat to the brine channel. 